\title{
Ant Colony Optimization-based Micro-grid Multi-Objective Optimization
}

\author{
Feng Xian Zheng* \\ Power grid operation and training department \\ State Grid Sichuan Electric Power Company Skill \\ Training Center \\ ChengDu,China \\ e-mail: fengxianzheng@qq.com
}

\author{
Li Hong Jun \\ Power grid operation and training department \\ State Grid Sichuan Electric Power Company Skill \\ Training Center \\ ChengDu ,China \\ e-mail:271237358@qq.com
}

\author{
Zhang Ting Ting \\ Power grid operation and training department \\ State Grid Sichuan Electric Power Company Skill \\ Training Center \\ ChengDu ,China \\ e-mail: 1062029444@qq.com
}

\author{
Zhao Bin \\ Power grid operation and training department \\ State Grid Sichuan Electric Power Company Skill \\ Training Center \\ ChengDu ,China \\ e-mail: $348941671 @$ qq.com
}

\begin{abstract}
Micro-grid is a hot issue in new energy research, and a major orientation of distributed power generation in the future. The diversity and flexibility of distributed power generation complicates the operation and scheduling optimization of micro-grid. On the basis of considering a mathematical model that contains photovoltaic cell, winddriven generator, storage battery, fuel cell, micro gas turbine and diesel-driven generator, the paper considers the operating cost and emission model of micro-grid, and proposes an ant colony optimization-based micro-grid optimization model with the goal of minimizing grid loss, operation and maintenance cost and emission load. The ant colony optimization adopted can complete optimal solution search through environment, foraging, movement, obstacle avoidance and pheromone, etc., and search for an optimal solution independently simultaneously at multiple spatial points, so it has a higher global searching capability, convergence rate and robustness. The simulation experiment in the calculation example proves the validity of the model and method.
\end{abstract}

Keywords-Micro-grid; multi-objective optimization; ant colony optimization; cost modle;emissionmodle

\section{INTRODUCTION}

The hot issues currently researched in energy industry include renewable energy and distributed energy. Distributed generation generally includes photovoltaic generation, wind power generation and micro water power generation, non-renewable energy includes fuel cell, diesel-driven generator and micro gas turbine, etc., and energy storage system includes such devices as storage battery, etc. The micro power grid made up of renewable energy, non-renewable energy, load and energy storing device is known as a micro-grid. Distributed generation has such advantages as low environmental pollution, low user cost, low line loss, high power quality and high power distribution reliability, but it also has such defects as intermittency, instability and uncontrollability, etc. On the premise of meeting the requirements of system load and normal distributed power supply operation, to optimize the reasonable installing position and installation capacitance of micro-grid and the choice of micro power supply type will affect the investment cost and operating cost of micro-grid and the contamination of environment ${ }^{[1-4]}$.

An optimal dispatching model with consideration to the coordination between energy conservation, water use and grid is built in Literature [5], and electromagnetismlike mechanism is used to solve the multi-objective optimal dispatching model. An economical model is built in Literature [6] under multi-constraints to minimize the operating cost of micro-grid, and an improved differential genetic algorithm is adopted for solving. An improved particle swarm optimization and hierarchical processing method is used to solve the multi-objective optimization problem in Literature [7], with a multi-objective lowcarbon dispatching strategy developed for micro-grid. A mathematical model with consideration to shedding load operation is built in Literature [8] for the power optimization of micro-grid by taking the total revenue maximization of micro-grid as an objective function, and artificial physics optimization (APO) is used for solving. A local equivalent circuit model is built for micro-grid based on neural network in Literature [9]. By taking minimum operating cost, network loss and emission load as an objective function, this paper builds a multiobjective model with consideration to the operating cost and emission model of micro-grid, and uses ant colony optimization for solving. The feasibility and validity of the model and algorithm are verified through a calculation example. A stochastic programming model and method for the united dispatching of wind power and hydropower is proposed in Literature [10]. Based on stochastic programming theory, with expected joint gain value maximization as a goal, with consideration given to the 
restriction from such two random factors as electricity price and wind power as well as transmission capacity in market environment, GAMS software is adopted for solving.

\section{Micro Grid SySTEM STRUCTURE AND MicRO POWER SOURCE MODEL}

\section{A. Micro Grid Structure}

The power source in a micro-grid contains multiple energy generation forms, including renewable energy generation (such as wind power generation and photovoltaic power generation, etc.), non-renewable energy generation (such as micro gas turbine and fuel cell, etc.), and energy storage system (such as storage battery), etc. Micro grid structural schematic diagram is shown in Fig.1.

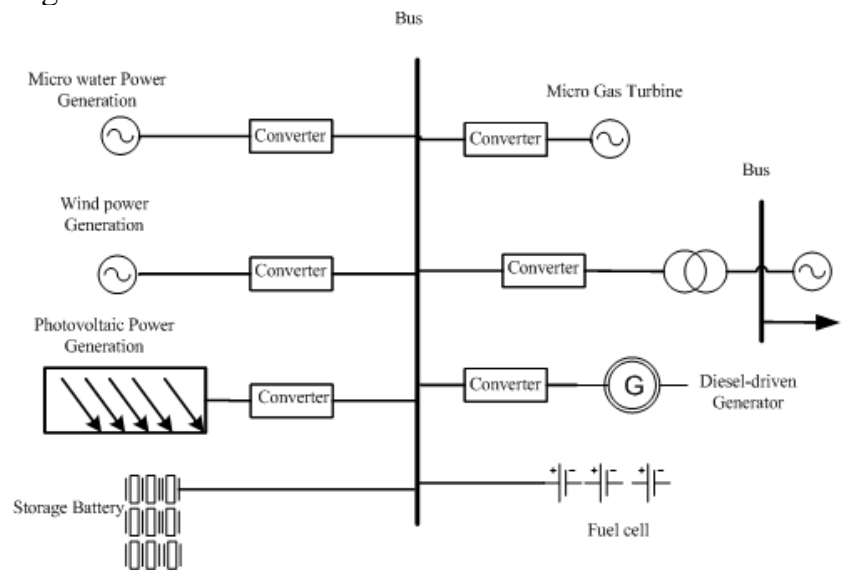

Figure 1. Micro Grid Structural Schematic Diagram

\section{B. New Energy Generation Model}

\section{1) Photovoltaic Power Generation}

The output power of photovoltaic battery has nonlinear characteristics, and is affected by illumination intensity, ambient temperature and load condition. The intensity of the sunlight can be approximately considered as obeying Beta Distribution within a given period of time (one hour or several hours), and the surface temperature of photovoltaic battery is related to light intensity and ambient temperature, able to be calculated in accordance with the following empirical formula[7]:

$$
T(t)=T_{\text {air }}(t)+30 \times \frac{G(t)}{1000}
$$

where, $T(t)$ denotes the temperature of battery at moment $\mathrm{t}$, and ${ }^{T_{\text {air }}(t)}$ denotes the ambient temperature at moment t. $G(t)$ denotes the actual light intensity during this period of time. to[7]:

The output power of photovoltaic array is approximate

$$
P_{P V}=P_{S} \frac{G(t)}{G_{S}}\left[1+k\left(T(t)-T_{S}\right)\right]
$$

where, $P_{P V}$ denotes the output power at moment $\mathrm{t}, G_{S}$ denotes the light intensity in a standard experiment condition $(1000 \mathrm{~W} / \mathrm{m} 2,250 \mathrm{C}) T_{S}$ denotes the temperature of photovoltaic array in a standard experiment condition, and $P_{S}$ denotes the maximum output power in a standard experiment condition. $\mathrm{K}$ denotes temperature coefficient, which is generally equal to -0.45 .

2) Wind Power Generation

According to the operating principle of wind turbine generator, in the operational process of wind power generation system, when wind speed is greater than cut-in wind speed, wind turbine generator system will begin to generate power, and generation output power will have a linear relation with wind speed; when wind speed is less than cut-in wind speed, wind turbine generator system will not generate power; after wind speed exceeds rated wind speed, wind turbine generator system will output electric energy at rated power; when wind speed is greater than cut-in wind speed, wind turbine generator system will halt to prevent a safe failure from being caused by blade stalling. Wind turbine generator system's power output model can be described with a segmented function.

$$
\begin{aligned}
P_{W} & = \begin{cases}0 & v \leq v_{c i}, v \geq v_{c o} \\
a v^{2}+b v+c & v_{c i}<v<v_{r} \\
P_{r} & v_{r} \leq v<v_{c o}\end{cases} \\
\text { Grid } b & =\frac{P_{r}}{v_{r}-v_{c i}} \\
c & =-a \cdot v_{c i}
\end{aligned}
$$

where, $a, b$ and $c$ are the characteristic parameters of wind turbine power, and $a$ is considered equal to 0 in approximate calculation, that is, wind speed has a linear relationship with output; $\operatorname{Pr}$ is the rated output power of wind turbine generator; vci and vco are cut-in and cut-out wind speed respectively; vr and $\mathrm{v}$ are rated wind speed and actual wind speed respectively.

3) Fuel Cell

The generating cost of fuel cell has something to do with its generating capacity and generating efficiency. The calculation formula for the daily generating cost of fuel cell can be expressed as follows:

$$
C_{F C}=c_{f c} \times T \frac{1}{L H V} \times \sum_{J} \frac{P_{J}}{\eta_{J}}
$$

where, Cfc denotes gas price, equal to 2.02 yuan, $\mathrm{T}$ denotes the running time of fuel cell, LHV denotes the low heating value of gas, equal to $9.7 \mathrm{kWh} / \mathrm{m} 3, \mathrm{PJ}$ denotes the net power output during time $\mathrm{J}$, and $\eta_{J}$ denotes the gross efficiency of cell during time $\mathrm{J}$.

4) Diesel-driven Generator

When diesel runs, fuel consumption will bear on power output, which can be described with quadratic polynomial, details below:

$$
C_{f D}=a_{i} P_{D L}^{2}(t)+b_{i} P_{D L}(t)+c_{i}
$$

where, $\mathrm{CfD}(\mathrm{t})$ denotes the cost of the fuel consumed in diesel at moment $t$; PDL denotes the output power of diesel at moment $t$; $i$ denotes the number of diesel-driven generator; ai denotes the quadratic coefficient of the expression, bi denotes the monomial coefficient of the expression, and ci denotes the constant coefficient of the expression.

\section{5) Micro Gas Turbine}

According to the relation curve between the output power and generating efficiency of gas turbine in some load conditions described in the instructions, polynomial 
curve fitting is carried out through MATLAB, with a relation function between the output power and generating

$$
\eta_{e}=0.0753\left(\frac{P_{M T}}{65}\right)^{3}-0.3095\left(\frac{P_{M T}}{65}\right)^{2}+0.4174\left(\frac{P_{M T}}{65}\right)+0.1068
$$

$\eta_{e}$ denotes the generating efficiency of micro gas turbine, and $P_{M T}$ denotes the output power of micro gas turbine at moment $t$.

6) Storage Battery

The performance of storage battery is generally described with the following three parameters: battery capacity, state of charge (SOC) and depth of discharge (DOD). The concrete relationship between the three is shown below:

$$
Q_{\text {sum }}=Q_{r}+Q \quad S O C=\frac{Q_{r}}{Q_{\text {sum }}} \quad D O D=\frac{Q}{Q_{\text {sum }}}
$$

where, Qsum denotes the total capacity that storage battery can output in the nominal working conditions, Qr denotes the residual capacity of storage battery, and $\mathrm{Q}$ denotes the output capacity of storage battery.

Multi-objective Optimal Dispatching Model of Microgrid

The optimal allocation of the multi-objective optimal dispatching model of micro-grid refers to that the position, capacity and type of the power source in micro-grid are optimized with grid loss, power generation investment, operating cost, maintenance cost and emission cost as targets on the premise that a series of constraint conditions, such as power equilibrium, installed capacity, node voltage, branch current and environmental factor, must be met. This is a nonlinear large-scale combinatorial optimization

$$
\min f_{2}=\sum_{i=1}^{n}\left[\alpha_{D G i} f_{D G i} P_{D G i}^{\text {rated }}+C_{D G i}^{\mathrm{var}}+C_{\text {airi }}+C_{e m i}+C_{e n}\right]
$$

where, $\alpha_{D G i}$ denotes the annual cost coefficient of the fixed investment in the ith micro power source, $f_{D G i}$ denotes the fixed investment in the unit capacity of the ith micro power source, and $P_{D G i}^{\text {rated }}$ denotes the rated capacity of the ith micro power source. $C_{D G i}^{\mathrm{var}}$ denotes variable cost, including operating, maintenance and fuel cost; $C_{\text {airi }}$ denotes the environmental pollution control cost and other social costs avoided by the use of new energy, $C_{e m i}$ denotes emission penalty cost, and $C_{e n}$ denotes the power purchase cost in micro-grid.

\section{Constraint Conditions}

\section{1) Load Flow Constraint}

$$
K_{U}\left(U_{i}\right)\left\{\begin{array}{l}
K_{u} \\
0
\end{array}\right.
$$

$$
\begin{gathered}
U_{i} \leq U_{i \min }, U_{i} \geq U_{i \max } \\
U_{i \min } \leq U_{i} \leq U_{i \max }
\end{gathered}
$$

where, $\mathrm{Ui}$ is the per unit voltage Value of node $\mathrm{i}$, Uimin and Uimax are the permissible minimum and maximum of node voltage respectively, and $\mathrm{K}$ is the border-crossing penalty value of voltage; Uimin $=0.95$ and Uimax $=1.1 \mathrm{Ku}=1000$.

4) Permissible Line Current Constraint

$$
I_{j} \leq I_{j \max }
$$

$$
\left\{\begin{array}{l}
P_{G i}-P_{L i}-U_{i} \sum_{j=1}^{N} U_{j}\left(G_{i j} \cos \delta_{i j}+B_{i j} \sin \delta_{i j}\right)=0 \\
Q_{G i}-Q_{L i}+Q_{C i}-U_{i} \sum_{j=1}^{N} U_{j}\left(G_{i j} \sin \delta_{i j}-B_{i j} \cos \delta_{i j}\right)=0
\end{array}\right.
$$

where, $P_{G i}$ and $Q_{G I}$ denote the active output and reactive output of micro power source respectively; $P_{L i}$ and $Q_{L i}$ denote the active load and reactive load of micro power source respectively; $Q_{C i}$ denotes reactive compensation capacity and $U_{i}$ denotes node voltage size; $G_{i j}$ and $B_{i j}$ denote system admittance.

\section{2) Capacity Constraint}

The installation capacitance of the ith micro power source is constrained as follows:

$$
P_{i \text { min }} \leq P_{i} \leq P_{i \text { max }}
$$

Subscripts max and min are the upper limit and lower limit of power respectively.

3) Node Voltage Constraint

where, Ij is the current in branch $\mathrm{j}$, and Ijmax is the permissible maximum current in branch $\mathrm{j}$.

\section{Ant Colony Optimization Solving}

Ant colony optimization is a bionic algorithm inspired by the foraging behavior of ants which search for the shortest path in a foraging process[11]. The core idea of ant colony optimization is that a secretion known as pheromone is used for the indirect communication within a 
colony. This pheromone has a positive feedback function, which enables all ants to choose the shortest path in the end. The local search strategy in ant colony optimization, the internal state of ants, the trail of pheromone and the decision of ants have a decisive effect on ants' search behavior.

During initialization, $\mathrm{m}$ ants are positioned over $\mathrm{n}$ targets, and each target function is given pheromone concentration (grid loss, the minimum sum of the annual allocated expense, variable cost and grid loss cost of fixed investment, and the cost of environmental emission). After ants finish a complete optimizing process, calculate the amount of information and update the concentration of the pheromone in the target functions, and then start a new round of cycle. When the cycle index reaches the minimum number of iterations that is defined in advance, or all ants choose the same path, the whole program will terminate. The basic steps of ant colony optimization are shown below:

(1) Calculate the degree of similarity between ants according to the data set characteristics;

(2) Establish an ant colony similarity matrix based on the degree of similarity between ants;

(3) Search for the best ant nest in accordance with ant nest number and the constantly updated nest attributes;

(4) Let each ant's acceptance threshold be the equal of $\mathrm{T}$, and acceptance threshold $\mathrm{T}$ denotes the dynamically changing similarity function when each ant meets with other ants (composed of maximum similarity and average similarity);

(5) Iterate ant meeting for $\mathrm{N}$ times, and arrange ant nest according to the acceptance threshold generated during a meeting between two ants until a nest is arranged for each ant.

\section{CALCULATION EXAMPLE ANALYSIS}

\section{A. Calculation Example Description}

Select a micro grid system connected that contains photovoltaic power generation, wind power generation, fuel cell, diesel-driven generator, micro gas turbine and storage battery. Carbon emission coefficient is equal to the values in Tab.1, operation and maintenance cost is equal to the values in Tab.2, and the optimum operation parameters of micro-grid are shown in Tab.3. Considering that the output of photovoltaic power generation and wind power generation is affected by ambient temperature, illumination intensity and wind force, we forecast the output of these two generations before calculation. According to the historical data of a certain region, the forecasting data of the output of photovoltaic power generation and wind power generation is illustrated in Fig.2. There is a big difference in load data at different times in different seasons, so a typical load curve is selected, as is shown in Fig.3.

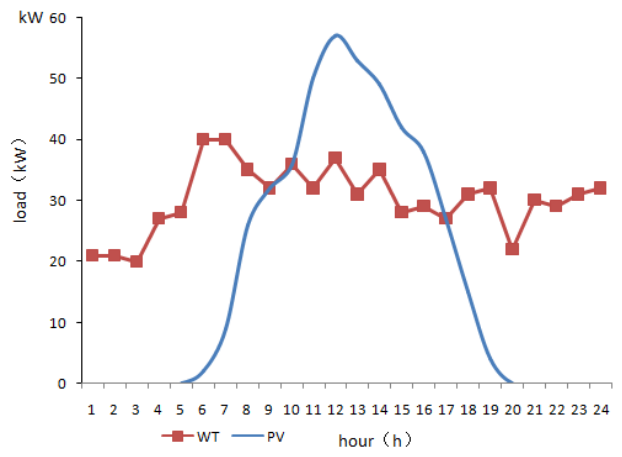

Figure 2. 24-hour Output Forecasting Data of Photovoltaic Power Generation and Wind Power Generation

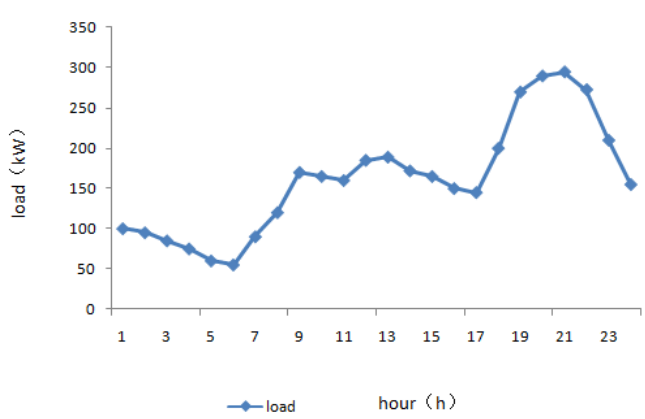

Figure 3. Typical Daily Load Curve

\section{B. Optimization Result Analysis}

The optimization calculation parameters selected for ant colony optimization are shown as follows: information heuristic value $\alpha=3$, expected heuristic value $\beta=4$, pheromone evaluation factor $\rho=0.45$, gross information content $\mathrm{Q}=1000$. For load flow calculation, NewtonRaphson algorithm is adopted. Minimum operating cost, grid loss and carbon emission is taken as an objective, and the output optimization result curve of each micro-grid is shown in Fig.4. It can be seen from the figure that renewable energy generation is characterized by high economical and environmental efficiency. Power purchase cost and carbon emission are relatively high. In micro-grid, each DG unit generates power according to upper power limit, and doesn't supply electric energy for micro-grid system unless load demand cannot be met. Carbon emission has a nonlinear relation with generated energy. An overall balance between economical efficiency, security and environmental efficiency is finally realized.

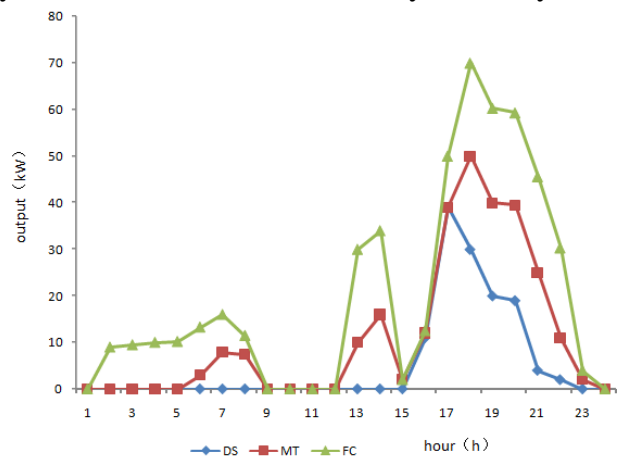

Figure 4. Output Optimization Result of Each Micro Power Source 
Tab I Operating Parameters of Micro Power Source

\begin{tabular}{cccc}
\hline Power Source Type & Operating Cost (yuan/kwh) & $\begin{array}{c}\text { Emission Coefficient } \\
(\mathrm{g} / \mathrm{kwh})\end{array}$ & $\begin{array}{c}\text { Allocation Capacity } \\
(\mathrm{kw})\end{array}$ \\
\hline Grid & 0.65 & 889 & - \\
Photovoltaic Power Generation & 0.013 & 0 & 65 \\
Wind Power Generation & 0.03 & 0 & 70 \\
Micro Gas Turbine & 0.2 & 725 & 100 \\
Fuel Cell & 0.32 & 490 & 35 \\
\hline
\end{tabular}

Tab II Economical Data of Micro Power Source

\begin{tabular}{|c|c|c|c|c|c|}
\hline Power Source Type & $\begin{array}{c}\text { Annual Cost } \\
\text { Coefficient }\end{array}$ & $\begin{array}{c}\text { Capacity } \\
\text { Coefficient }\end{array}$ & $\begin{array}{c}\text { Fixed Cost (10 } \\
\text { THS } \\
\text { yuan/kW) }\end{array}$ & $\begin{array}{l}\text { Penalty Cost } \\
\text { (yuan/kWh) }\end{array}$ & $\begin{array}{c}\text { Operation and } \\
\text { Maintenance } \\
\text { Cost } \\
\text { (yuan/kWh) }\end{array}$ \\
\hline Photovoltaic Power Generation & 0.05 & 0.33 & 4.55 & 0 & 0.01 \\
\hline Wind Power Generation & 0.1 & 0.43 & 1.3 & 0 & 0.03 \\
\hline Micro Gas Turbine & 0.1 & 1 & 0.97 & 0.0039 & 0.04 \\
\hline Fuel Cell & 0.1 & 1 & 1.8 & 0.008 & 0.03 \\
\hline
\end{tabular}

Tab III Pollutant Emission Data of Micro Power Source

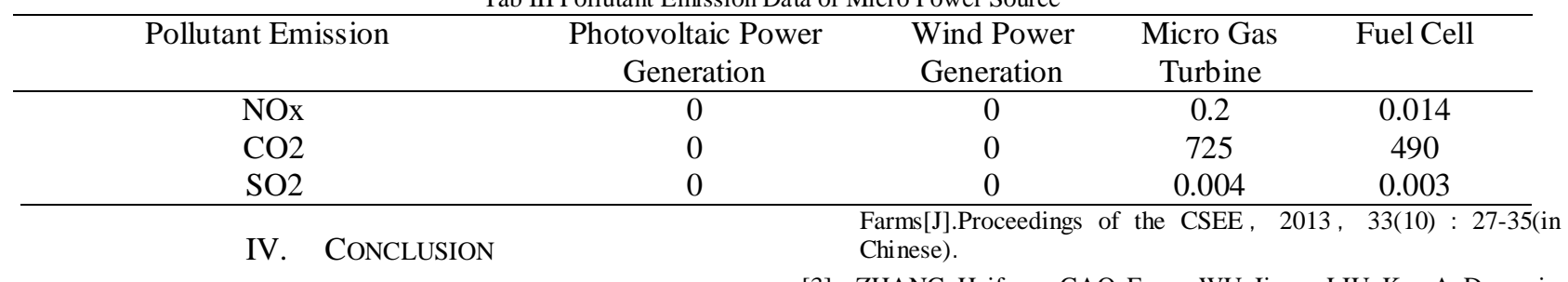

This paper analyzed the operating principle and characteristics of photovoltaic power generation, wind power generation, storage battery, diesel-driven generator, fuel cell and micro gas turbine, and built a mathematical model for each micro power source. Then, it proposed an ant colony optimization-based multi-objective, hierarchical optimization allocation method. Minimum grid loss was taken as an objective function at the first hierarchy for load flow calculation, with the load flow distribution of microgrid obtained and the installation site of micro power source determined; minimum annual micro-grid cost was taken as an objective function at the second hierarchy, with the capacity allocation and type of micro power source determined; carbon emission was taken as an objective function at the third hierarchy, with an optimal allocation scheme obtained for micro-grid. The calculation example verified the rationality of the mathematical model and the multi-objective, hierarchical ant colony optimization of micro-grid.

\section{REFERENCES}

[1] Sun shujuan. Research on The Optimal Configuration and Economic Operation Model for Multi-energy Micro-grid[D].Hefei University of technology,2012(in Chinese).

[2] CHEN Gonggui,CHEN Jinfu.Environmental/Economic Dynamic Dispatch Modeling and Method Including Wind
[3] ZHANG Haifeng, GAO Feng, WU Jiang, LIU Kun.A Dynamic Economic Dispatching Model for Power Grid Containing Wind Power Generation System[J].Power System Technology, 2013, 37(5) : 1298-1303(in Chinese).

[4] HONG Bowen, GUO Li, WANG Chengshan, JIAO Bingqi, LIU Wenjian.Model and method of dynamic multi-objective optimal dispatch for microgrid[J].Electric Power Automation Equipment, 2013, 33(3) : 100-107(in Chinese).

[5] GUO Zhuangzhi, WU Jiekang, KONG Fannie.Multi-objective Optimization Scheduling for Hydrothermal Power Systems Based on Electromagnetism-like Mechanism and Data Envelopment Analysis[J]. Proceedings of the CSEE, 2013, 33(4) : 53-61(in Chinese).

[6] WANG Bo-yi, WANG He, LAN Sen, LI Jia-peng.Optimal Operation of Microgrid Based on Improved Differential Evolution Algorithm[J]. Journal Of Northeast Dianli University, 2013, 33(1/2) : 27-32(in Chinese).

[7] Liu Wensheng. Microgrid Layout Optimization and Low Carbon Scheduling Using Particle Swarm Algorithm[D].Guangdong University of Technology,2012(in Chinese).

[8] ZHAN Xin, XIANG Tieyuan, ZENG Shuang, XIONG Hu, XU Qingzhong.Microgrid power optimization based on artificial physics optimization algorithm.Electric Power Automation Equipment, 2013, 33(4) : 44-48(in Chinese).

[9] Feng Yanjun.The equivalent modeling and stability analysis of microgrid based on neural network[D].Yanshan University.2012.

[10] Wang WenFeng.Coordinated operation model and method for wind power-hydro plants[D].GuangXi University.2012.

[11] Lu Tianyu.Research and Application of Genetic Ant Colony Hybrid Algorithm[D].XiAn University of Science And Technology,2012. 